\title{
Transformation of Strategic Management in the Digital Economy (on the Example of Air Transport)
}

\author{
Sergey Demin ${ }^{1}$, Nikolay Stolyarov ${ }^{2}$, Alla Semenova $^{3}$, and Margarita Kuzina ${ }^{4}$ \\ ${ }^{1}$ Moscow Aviation Institute (National Research University), 125993 Moscow, Russian Federation \\ ${ }^{2}$ State Research Institute of Civil Aviation, 125438 Moscow, Russian Federation \\ ${ }^{3}$ G.V. Plekhanov Russian Economic University, 117997 Moscow, Russian Federation \\ ${ }^{4}$ Russian New University, 105005 Moscow, Russian Federation
}

\begin{abstract}
Globalization, which presupposes the strengthening of multifactorial economic, social and other phenomena, needs strategic management, forecasting and foreseeing its impact on every spheres of public life without any exception. Unfortunately, the modern Russian strategic planning system appears to be unbalanced and ineffective; key indicators of the adopted and developed strategies are abstract in nature and are weakly correlated with the practical needs. This is clearly illustrated by the example of such an important branch of the economy as transport. Strategic air transport management in Russia in the context of the digital transformation of the economy, especially the practice of strategic planning and forecasting, has a number of bottlenecks and needs to be improved. A very vulnerable spot in modern strategic management is the occasional use of methods of strategic audit (control). This conclusion is confirmed by the analysis of the draft Transport Strategy for the period up to 2035, submitted for discussion and revision. It is not possible to solve this problem without scientific support and methods of strategizing approved by domestic and foreign practice.
\end{abstract}

\section{Introduction}

In the modern system of corporate governance - both in Russia and abroad - the issues of strategizing are gaining increasing importance. So, in order for the enterprise to be competitive, the industry successfully developed and made a profit, and the economy as a whole was viable for any test, it is necessary in management to achieve conceptual clarity, analytical harmony, understanding of the internal logic of the controlled system when making the decisions. And on this basis, one shall foresee and predict the consequences of the decisions made, which is an objective necessity of corporate governance. Let's take a look at the example of air transport, a strategically important branch of the economy. 


\section{Methods of analysis and forecasting of air transport development}

\subsection{What will aviation be like after the pandemic crisis?}

Strategic vision for the future of aviation is becoming increasingly important in a pandemic. After all, everything that is happening today in world and Russian civil aviation is due to the crisis caused by the pandemic. The crisis has had its destructive effect on every components of the transport complex of Russia, including civil aviation. A sharp decline in passenger air traffic (from $30 \%$ to $70 \%$ of passenger turnover), which suddenly became a critical financial situation of many airlines, the forced reduction by aircraft manufacturers in the release of new aircraft - these and other problems caused by the pandemic are growing like an avalanche and negatively affect almost all spheres of economic life of the country.

The crisis is not eternal; someday it will inevitably be overcome. And today we need to look far ahead, trying to clearly define the guidelines for the development of civil aviation. At the same time, it is important not to be captivated by established and outdated stereotypes. It is quite obvious that after emerging from the crisis, civil aviation will no longer be the same. Experts in the field of civil aviation predict that the air transportation market will revive in about a year and its capacity at the beginning will be half of the pre-crisis one (at best). Airline executives share these expectations. However, there are more pessimistic forecasts, based on the fact that the measures taken to restore the industry are not enough, that it will hardly be possible to change the mistrust in air transport in the near future that has already arisen.

Indeed, there are no proper grounds for rosy forecasts:

- current operating costs and urgent financial liabilities of airlines continue to grow and there is no need to count on government assistance in the required amount in the event of a federal budget deficit;

- world aircraft manufacturers have already announced a significant (by 40\%) reduction in the production of passenger aircraft, and it is quite obvious that the products of domestic aircraft manufacturers are not yet able to be competitive in order to meet the need for new aircraft and technologies; $73.5 \%$ of the Russian aircraft fleet is represented by foreign products, and of the remaining $26.5 \%$, half of the aircraft entered service in Soviet times;

- $\quad$ system of training and retraining of aviation personnel, including modern training technologies, remains conservative and unable to adequately respond to the challenges generated by the crisis;

- transport accessibility of sparsely populated and hard-to-reach regions of the country still remains an insoluble problem inherited from the past; for comparison: in the United States there are 76.5 small aircraft per 100,000 population, while there are only 3.1 in our country.

Taking into account the above and other factors that influence the dynamics of the restoration of air traffic in Russian air transport, we will proceed from the moderately conservative option presented in Figure 1 [1]. 


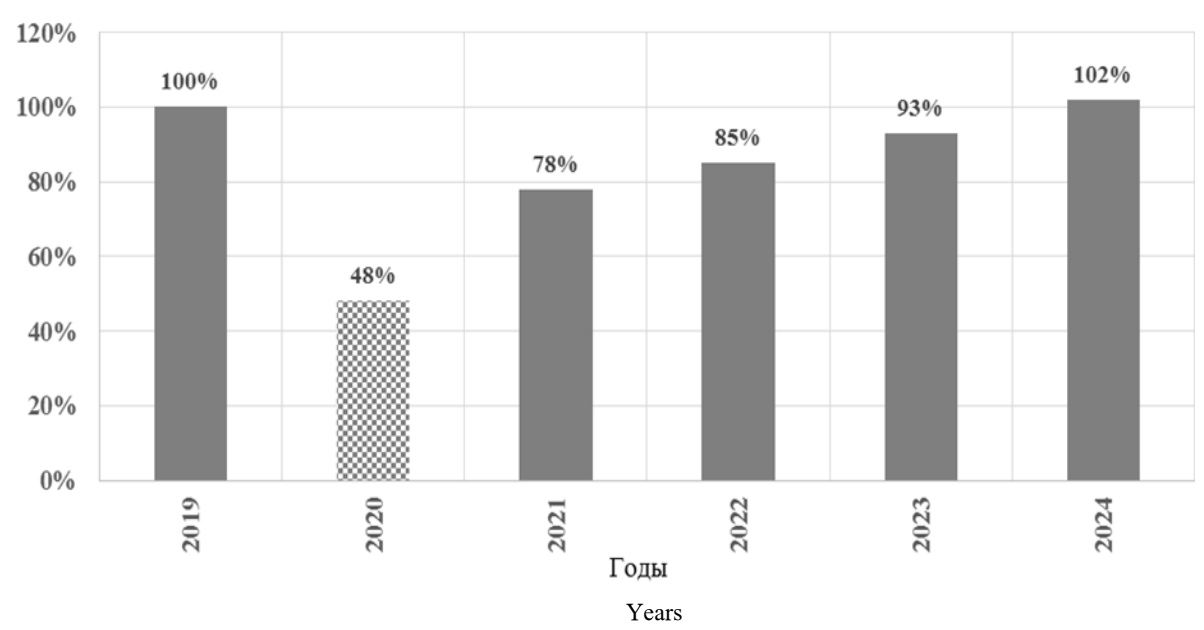

Fig. 1. Forecast for the recovery of air traffic in Russian air transport (moderately conservative scenario), \%, by 2019

The list of problems of civil aviation, aggravated by the crisis caused by the pandemic, could be continued, but what has been said is enough to conclude: without diminishing the importance of operational and tactical (current) post-crisis measures, it is necessary to urgently and scientifically develop a long-term development strategy for air transport, providing for phased planning of movement towards the intended goal, namely, the formation of a new image of civil aviation.

\subsection{State and prospects of digital transformation of air transport}

The new paradigm of the strategy for the development of air transport is caused not only (and not so much) by the rapidly bursting pandemic into our lives. The revision of landmarks in the field of civil aviation is long overdue and is associated with total digitalization. The digital technology segment is taking an increasingly important place in the development of transport infrastructure and supply chains and is a global trend in the context of the New Globalization (R.P. Baldwin). Signs of a new stage of globalization are a decrease in the cost of distribution of goods in space, a reduction in communication costs and a reduction in the cost of moving people [2].

Unfortunately, modern Russia does not play a leading role in this process, but in fairness, it should be noted that our country has done and is doing a lot for the digital transformation of the transport complex in recent years. Thus, the Unified State Information System for Transport Security (EGIS OTB) has been created, which makes it possible to reliably control passenger transportation - from an individual passenger to a specific vehicle. This system was highly appreciated by foreign partners and recognized as one of the best among similar systems used in world practice.

Aeroflot has tested and implemented a digital technology that makes it possible to monitor the technical condition of aircraft units and assemblies during the flight. A huge flow of information is transmitted to the ground service of maintenance and repair and is systematized therein, which makes it possible to ensure timely replacement of worn out parts, and most importantly - to improve aviation security. 
The digital transformation of airports will require significant funding. The airport of the future is a whole ecosystem capable of processing a huge amount of data and minimizing waiting times at the checkpoints. All over the world, the range of the services provided by the airports is constantly expanding. For this purpose, logistics and trade terminals are being transformed into large economic centers - the so-called airport-cities (aerotropolis), capable of comprehensive customer-oriented passenger service.

It can be assumed that digital transformation will have significantly change the air transportation market by 2025. By this time, the majority of the world's population will be represented by post-digital generations who grew up in online services in everyday life and are used to using their mobile devices as "life control panels". Even today, 54.5\% of air passengers use online check-in through a mobile application, website, and automatic checkin services at the airport. By $2021,79 \%$ of airlines plan to introduce baggage tracking services [3].

Of course, the digital transformation of air transport cannot be a conglomerate of separate, disparate innovations, but is a systemic movement into the future, towards a new technological order, which in turn presupposes systemic strategic planning.

\subsection{Attempts at strategic planning for the development of the transport system of the Russian Federation}

Almost 30 years have passed since the US adopted the law on strategic planning, which does not exclude, but, on the contrary, presupposes the strictest state control over the implementation of strategic plans and programs. At the same time, neoliberal reforms began in Russia, as a result of which the Soviet system of strategic planning was abolished and subsequently lost. Even the concept of "planning" in those days was considered something reprehensible and unacceptable for market reforms.

What do we have today? There is practically no system of strategic planning in the Russian Federation, the goals of the authorities are not linked with each other and with the requirements of the President and the Government and do not coincide with the project activities of the Government, are determined formally, and their achievements are not monitored. This is a disappointing conclusion, not made by the authors of the article, but by the independent body of state audit (control) - the Audit Chamber of the Russian Federation - based on the results of an expert and analytical event dedicated to strategic audit of the formation and achievement of performance indicators of federal executive bodies. [4].

In addition, the Audit Chamber notes that the system of strategic planning of the executive branch's activities is currently unbalanced and ineffective, insufficiently regulated and methodically supported.

In 2014, the federal law "On Strategic Planning in the Russian Federation" was adopted (No. 172 - Ф3 dated June 28, 2014). However, it did not meet the expectations and did not become the basis of the state strategic planning system. Today, the need for significant clarifications and amendments to the law has become obvious. Everyone has gone to it for almost a quarter of a century!

Thus, it can be stated with a good reason that there is no full-fledged strategic planning system in modern Russia: strategies are adopted without scientifically based forecasts and are often imitated in nature, strategic audit (control) over the implementation of strategic plans and programs is not properly established, the necessary adjustments and additions to the adopted strategies are made from case to case, or even not at all. Unfortunately, the Transport Strategy of the Russian Federation for the period up to 2030, approved by the Order of the Government of the Russian Federation No. 1734-p dated November 22, 2008, was no exception in this regard. 
After almost six years of implementation of this strategy, it turned out that it has significantly lagged behind real practice over the years. There was an obvious need for its updating and renewal, which was soon done. The Government of the Russian Federation approved a new version of the Transport Strategy for the period up to 2030 (No. 1032-p dated June 11, 2014).

The 400-page document contained two options for development: basic (conservative) and innovative ones. The preference was given to the second option, which, as expected, would make it possible to achieve the availability of transport services for the population at the level of developed countries and in accordance with safety standards.

The tasks are truly ambitious and important for the state. Over the years, a lot has been done to improve the quality of service for air passengers. In 2019, Russian airports handled more than 221 million passengers - the highest figure in all 95 years of Russian civil aviation history. However, despite the efforts made, it is difficult to say that the strategy is successfully being implemented. The main reason, in our opinion, should be sought in the lack of ability to predict in the medium and long term, and in the future, competently and effectively bring the idea to its logical conclusion, while applying an underestimated strategic audit (control), the results of which could be corrected and the plans changed; anticipate risks, threats and challenges.

\subsection{A new turn in the strategic planning of the transport complex}

The transport strategy of the Russian Federation until 2030, like many of its analogues, ceased to exist in the middle of the road. By a bureaucratic expression of will, the updated strategy was consigned to oblivion and instead a draft of a new Transport Strategy of the Russian Federation appeared - now for the period up to 2035.

Presenting the draft of a new transport strategy to the Government of the Russian Federation, M.V. Mishustin defined its goal as "to formulate a modern transport infrastructure, which is necessary for the development of the country and the achievement of national goals. It is necessary to set such dynamics in the industry so that its growth outstrips the demands of other sectors of the economy, so that people and business can receive affordable, high-quality, new, technological and safe services at any time" [5].

How does the new transport strategy differ from its predecessor? First of all, in its volume (60 pages), lack of excessive detailing, focus on national projects, innovative nature - one of the most significant results of the strategy implementation should be the introduction of digital technologies in all types of transport and transport activities.

The strategy is expected to be implemented in two stages. The first stage is being implemented from 2020 to 2024, the second stage - from 2025 to 2035 . At the first stage of the strategy, the task is set for the Russian Federation to become one of the 5 largest economies in the world and ensure economic growth rates higher than the world ones while maintaining macroeconomic stability (including inflation at a level not exceeding 4\%). At the second stage, the transition to the accelerated development of the transport system of Russia should be carried out.

By 2035, for the implementation of the Strategy's measures, it will be necessary to fully (!) provide domestic-made aircraft for the needs of regional and small aviation, as well as general aviation.

The tasks are strategically important. Their solution will require significant material resources, effective management, state patronage and control. The successful implementation of the Strategy will, as expected, contribute to the connectivity of the territories of Russia, the sustainability of the functioning of transport as a single industry. 


\section{Ways to improve strategic air transport development plans}

The draft of the new Strategy has not received full approval. The government basically approved the project and sent it back for revision. And there is something to work on - and not only because there are no limits to improvement; indeed, the document contains many bottlenecks. What, in our opinion, are the ways to improve the discussed project?

First, the document's excessive optimism is embarrassing: all forecast indicators are growing without encountering any obstacles in their path. But in a turbulent, rapidly changing world there are many threats and risks that can seriously affect the implementation of strategic plans. However, the strategy has no alternative; of all possible scenarios, the developers chose the simplest and the most optimistic one. One cannot but remember that globalization has not only pros but cons as well. They are well known. Many analysts even predict the end of the era of globalization, which will inevitably have a negative impact on the state of regional economies.

Secondly, the developers want to gradually shift the financial burden in the interests of achieving the strategic goals and objectives from the state to the users of transport services ("the user pays"). In our opinion, this short-sighted liberalization of the transport system can significantly complicate the implementation of the Strategy. This is primarily a matter of national security. The transport arteries of the country must be developed with the active participation of the state and be under its constant control. The efficiency of air transport will inevitably increase from this. Just one example to prove it. Last year, the volume of passenger traffic on domestic routes increased by $7.4 \%$ (compared to the previous year) and amounted to 135.4 billion passenger-kilometers. This was largely facilitated by the long-term state policy on the implementation of subsidy programs aimed at increasing regional air traffic, ensuring the availability of passenger transportation to the Far East, Simferopol, Kaliningrad and other regions of the country.

Thirdly, it is impossible not to pay attention to the fact that the priority in the strategy is given to railway and other modes of transport. For all their importance, air transport should not be given a secondary place, which has found itself in a very difficult situation and needs government support. Thus, a comparative analysis of the civil aviation regulatory framework of ICAO (International Civil Aviation Organization) and the Russian Federation was not in our favor; it is required to update all federal aviation rules, orders and instructions [6]. The certification system for civil aviation technology needs to be improved. Many experts, including those from the Audit Chamber of the Russian Federation, consider the implementation of the state program for the development of the aviation industry of the Russian Federation until 2025 as ineffective.

Fourthly, strategic management is not just planning, but analysis, organization, correlation of declared strategic goals, and control as well. Strategic audit (control) in organic unity with traditional financial audit and monitoring of the effectiveness of the use of available resources is able to ensure high effectiveness of strategic management [7]. Unfortunately, the Strategy not only does not specify, but does not even indicate a control mechanism - both internal and external ones. However, today this is the weak point of many adopted and developed strategies.

Fifth, the draft Strategy does not pay enough attention to assessing the effectiveness of the results achieved. For this purpose, in our opinion, it is advisable to use COBIT-5 methodology (Control Objectives for Information and Related Technologies) [8]. This study conceptualizes the factors of management in the field of information technology, allowing to assess processes in order to increase the effectiveness and rationality of the organization. 


\section{Conclusion}

1. The post-crisis scenario for the restoration of air transport cannot be overly optimistic and, in our opinion, is improbable. To implement the optimistic version of the recovery of the air transport market, a lot is needed to be considered, including both external and internal factors. And the main thing here is that the further march of the coronavirus pandemic is still difficult to predict.

2. Macroeconomic stabilization and the recovery process of the Russian economy will make it possible to revive the country's air transport complex. It should be borne in mind that recovery will take place on the basis of market mechanisms, which does not exclude, but on the contrary, presupposes the necessary and sufficient organizational and financial support from the state.

3. Effective implementation of the goals and objectives of the new version of the Strategy, most of which are innovative in nature, is impossible without scientific support, without reliance on science. In our opinion, in order not to repeat the mistakes made, the Russian scientific community, including the representatives of higher educational institutions of Russia, could and should take on the issues of finalization and scientific and methodological support for the implementation of the transport strategy proposed for discussion, taking into account new economic realities [9].

\section{References}

1. V. Filev, Passenger traffic will fall by half after the end of the crisis, Internet news portal Kommersant Publishing House, https://www.kommersant.ru/

2. R. Baldwin, Economic Sociology, 18(5), 40 (2017)

3. I. Shatilin, How air transportation will change in 5 years, thanks to digital technologies, Frequent Flyers.ru (2019)

4. Expert and analytical event: "Strategic audit of the formation and achievement of performance indicators of federal executive bodies, which are managed by the Government of the Russian Federation, in 2017 - 2018 and the past period of 2019", Bulletin of the Audit Chamber of the Russian Federation, 1(266) (2020)

5. M.V. Mishustin, Opening remarks at the meeting of the Government of the Russian Federation, Transcript of the meeting of the Government of the Russian Federation, March 26, (2020)

6. S.S. Demin, N.S. Stolyarov, A.A. Semenova, Prospects for the development of air transport in the context of globalization: monograph, 232 (2019)

7. N.S. Stolyarov, A.A. Semenova, Actual problems of socio-economic management in Russia, 4, 19 (2018)

8. D. Enriquez, R. Pereira, R. Almeida, M. Mira da Silva, Foresight, 14(1), 48 (2020)

9. S.S. Nosova, S.V. Makar, G.P. Sorokina, A.A. Semenova, S.A. Bondarev, Espacios, 41(27), 10 (2020) 